\title{
CORRECTION
}

\section{Correction to: Cesarean delivery to prevent anal incontinence: a systematic review and meta-analysis}

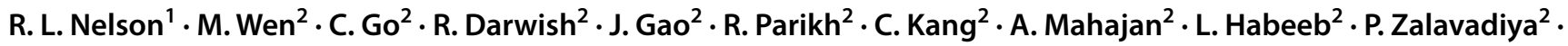 \\ M. Patnam ${ }^{2}$
}

Published online: 16 August 2020

(c) Springer Nature Switzerland AG 2020

\section{Correction to: Techniques in Coloproctology https://doi.org/10.1007/s10151-019-02029-3}

Unfortunately, one co-author, Mellissa Wen, name was missed out in the original publication. The complete correct author group is given below.

R. L. Nelson ${ }^{1}$, M. Wen ${ }^{2}$, C. Go ${ }^{2}$, R. Darwish ${ }^{2}$, J. Gao $^{2}$, R. Parikh $^{2}$, C. Kang ${ }^{2}$, A. Mahajan ${ }^{2}$, L. Habeeb ${ }^{2}$, P. Zalavadiya ${ }^{2}$, M. Patnam ${ }^{2}$
Publisher's Note Springer Nature remains neutral with regard to jurisdictional claims in published maps and institutional affiliations.

The original article can be found online at https://doi.org/10.1007/ s10151-019-02029-3.

R. L. Nelson

altohorn@uic.edu

1 Epidemiology/Biometry Division, University of Illinois School of Public Health, Chicago, IL, USA

2 Honors College, University of Illinois at Chicago, Chicago, IL, USA 